\title{
The Study on the Characteristics of Pressure Arch above the Twin-Parallel Openings in the Jointed Rock Masses
}

\author{
Kunpeng Gao $\mathbb{D}^{\mathbb{D}},{ }^{1}$ Kang Liang $\mathbb{D}^{\circ},{ }^{1}$ Leyao Wang, ${ }^{1}$ Changhao $L i,{ }^{2}$ Jinghai $Y u,{ }^{1}$ and Runyi Wu ${ }^{1}$ \\ ${ }^{1}$ Nanjing Vocational University of Industry Technology, Nanjing 210023, China \\ ${ }^{2}$ Yuwu Mining Co.Ltd., Lu'an Group, Changzhi 046103, China \\ Correspondence should be addressed to Kang Liang; liangk@niit.edu.cn
}

Received 29 November 2021; Accepted 12 February 2022; Published 8 March 2022

Academic Editor: Gaofeng Song

Copyright $(0) 2022$ Kunpeng Gao et al. This is an open access article distributed under the Creative Commons Attribution License, which permits unrestricted use, distribution, and reproduction in any medium, provided the original work is properly cited.

The self-bearing capacity of the rock masses has been a hot pot in the research of supporting technology in underground engineering. The pressure arch has been considered the main hypothesis to explain the self-bearing capacity of the rock masses. In this paper, the engineering of the twin-parallel openings in the jointed rock masses was selected as the background of the research. The characteristics of the deformation or the movement of the rock masses above the openings were studied based on the pressure arch theory. The difference between the single opening and the twin-parallel openings has been revealed, and the mechanism has also been illustrated. Besides, the joints' strength, the in situ stress ratio, the distance between the two openings, and the excavation sequence were selected as the variable parameters, and their influences have also been illustrated by the DEM method.

\section{Introduction}

With the development of underground engineering, the engineering of the twin-parallel openings has been gradually more and more frequently encountered in mining or tunnel engineering. The more complicated regularity of the deformation and movement of the rock masses shall be induced by the neighbor opening, especially in the joint rock masses. It has brought new challenges to design the economic support to control the deformation and movement of rock masses under this engineering condition.

In underground engineering, the initial equilibrium within the rock masses will be disturbed when the opening is excavated, and the stress of the rock masses in the vicinity of the opening will be redistributed correspondingly and immediately. The rock masses around the opening will start to deform or move towards the excavation space until the supporting structure can bear the additional stress induced by the deformation or movement of the rock masses [1-6]. Formerly, the supporting structure only referred to the manmade construction, including the steel support, the concrete wall. With the going deep of the research work, the selfbearing capacity of rock masses has been revealed and been gradually considered as the primary factor to maintain the stability of the rock masses. The formation process of this understanding could be divided into three phases. Firstly, the self-bearing structure of rock masses was revealed, especially the concept of the pressure arch was formed. Secondly, the corresponding support design method, which was based on the concept that the main purpose of the supporting was to enhance the self-bearing capacity of the rock masses, was used for real engineering. This phase could be represented by the proposing and applying of the "New Austrian tunnelling method" [7-11]. And finally, this philosophy of the support design has been accepted by most scholars and engineers in the world, and how to improve the bearing capacity of the self-bearing structure of the rock masses and assist the rock masses in stabilizing itself have become a hot spot in the study of the underground engineering [12].

The arch effect is a common phenomenon in nature. This effect could help long-span structure remain stable and has usually been used to construct the bridge, the gymnasium, and other large space buildings. As a rule-of-thumb, the pressure arch of rock masses, which has a similar stress characteristic with the ordinary arch, has been considered as 
the main type of the self-bearing structure of rock masses. When the opening is excavated, the weight of the overburden has mainly been converted into compressive stress and transferred to the abutments through the pressure arch. The direction of the principal stress of the rock masses within the arch area has been deflected, and the stress value has elevated, while the stress of the rock masses below the arch area has decreased significantly. The overlying weight has been resisted by the pressure arch finally. The formation of a pressure arch could prevent the further deformation or movement of the rock masses [13-16].

Various relevant factors for the arch formation have been selected as the study objects. The cover depth and the in situ stress ratio have been considered as the most important factor which could influence the formation and the characteristics of the pressure arch $[15,17,18]$. As a rule-ofthumb, the greater depth and the greater in situ press ratio have a significant positive impact on the formation of the pressure arch and the stability of the opening, especially when the in situ stress ratio and the arching degree are lower. Besides that, the strength of the rock masses, the excavation roof rise-to-span ratio, and so on have also been considered and could be beneficial or adverse to the formation of the pressure arch in different engineering conditions. However, the influence has been slightly weak.

The method used to study the pressure arch of the rock masses has been mainly focused on the numerical simulation method or the simplified mechanical model. The in situ observation method has been seldom used due to economic and technical restrictions. The mechanical model has been built based on the Voussoir beam or the arch theory $[13,19-21]$. The thrust line could be used to evaluate the arch behavior of the rock masses [22]. Due to the complexity of underground engineering, the mechanical model has only assisted researchers in finding the relevant factors of the formation or the failure modes of the rock pressure arch. To further reveal the mechanism of the pressure arch, laboratory experiments, which mainly refer to the physical simulation experiment, have been employed [14, 20, 23]. To a certain extent, the physical simulation experiment could reflect the real regularity. However, the deeper mechanism of the pressure arch could not be revealed due to the monitoring methods and economic considerations. Hence the numerical simulation method has gradually become the priority method to research the pressure arch. The finite difference method (FDM, e.g., FLAC, FlAC3D) and the finite element method (FEM, e.g., ABAQUS, ANSYS), which are based on the continuous medium, have been widely used to reflect the redistribution of the stress and the development of the pressure arch under the various parameters or the different engineering conditions [15-18], [24-27]. However, the continuous medium method could not well reflect the regularity of the movement of the rock masses. The discontinuous faces, e.g., joints, faults, have a nonnegligible impact on the deformation of the rock masses. Hence, the numerical method which is based on the discontinuous theory has been gradually adopted to research the problem in underground engineering. The representative method includes the discrete element method (DEM, e.g., UDEC
[19], PFC3D [28]) and the discrete element discontinuous deformation analysis (DDA) [13, 21].

Previous studies have obtained the profound comprehension of the pressure arch in the surrounding rock masses of the opening. However, accurate evaluation of the characteristics of the arch distribution above the twin-parallel openings in the jointed rock masses is still a challenging task. The joint leads to the anisotropic deformation of the rock masses and weakens the strength of the rock masses and has a nonnegligible influence on the deformation of the rock masses. In addition, the neighbor opening shall inevitably influence the movement or the deformation of the surrounding rock masses of the other opening.

This paper aimed to gain an in-depth understanding of the characteristics of the pressure arch above the twin-parallel openings in the jointed rock masses. The difference of the pressure arch between the twin-parallel openings and the single opening was discussed. The friction angle of the joints $(\varphi)$, the in situ stress ratio $\left(K_{0}\right)$, and the distance between the twin-parallel openings $(L)$ were selected as the study parameters. Their effect was obtained by the numerical simulation method, respectively. With 20 groups of the numerical simulation, the characteristics of the pressure arch above the twin-parallel openings and the influence of the study parameters were analyzed in detail and clearly revealed.

\section{The DEM Model}

The chief stumbling block to research the pressure arch in the rock masses is that the pressure arch has been hard to investigate, and this difficulty has also limited the previous progress of understanding the pressure arch. With the numerical simulation method development, it becomes possible to observe the formation and the distribution of pressure arch directly and thoroughly. The discrete element method (DEM) is a discontinuous-based method, which treats the analysis domain as an assemblage of discrete blocks and is very suitable to the studies of jointed rock masses or blocky systems. It could well evaluate the influence of the discontinuous faces on the deformation or the movement of the rock masses by directly constructing the discontinuous faces (such as joints, faults) in the model. To achieve a clear understanding of the characteristics of pressure arch above the twin-parallel openings in the jointed rock mass, five series of numerical experiment were employed with the DEM method.

The laminated rock mass, which usually belongs to the sedimentary rock mass, was considered in this study. The laminated rock mass usually exhibits a geological structure known as "mechanical layering" where the joints are bounded by the bedding plane boundaries and usually nearly perpendicular to the bedding planes [13]. The laminated rock mass is frequently encountered in underground excavations in metro construction, the tunneling engineering, and coal or metal mining. Based on the structural features in the laminated rock mass, two sets of orthogonal discontinuous faces were constructed in the model, which simulated the vertical joints and the horizontal stratum faces, respectively. 
The numerical model was illustrated in Figure 1. The height of the research domain was $100 \mathrm{~m}$, and the width was $200 \mathrm{~m}$. The thickness of each rock layer was $1 \mathrm{~m}$, and the spacing between joints was also $1 \mathrm{~m}$. Both openings' span were set as $10 \mathrm{~m}$, and the distance between them was set as $L$.

The rock material was regarded as linearly elastic with $\rho=2700 \mathrm{~kg} / \mathrm{m}^{3}$, Young's modulus $E=10 \mathrm{GPa}$, and Poisson's ratio $v=0.25$. The joints' deformation and movement were assumed to follow the Coulomb-Slip model, with the tensile and cohesion strength set as zero to simplify the computation, and the friction angle of the joints $(\varphi)$ was selected as a variable in this study. The gravitational acceleration $g$ was set as $10 \mathrm{~m} / \mathrm{s}^{2}$, and the in situ (horizontal/ vertical) stress ratio $\left(K_{0}\right)$ changed in the range from 0.3 to 1.2 in this paper. Besides, the sequence of the excavation of the two openings was also considered in the simulation.

The two lateral sides of the model were fixed in the horizontal direction, and the bottom boundary of the model was fixed in the vertical direction.

The computation was divided into two stages. At the first stage, the vertical in situ stress $\rho g h$ and horizontal in situ stress $K_{0} \rho g h$ were added to the analysis domain, where $h$ was the overburden depth and $K_{0}$ was the in situ (horizontal/ vertical) stress ratio that was also called the lateral pressure ratio. An in situ stress equilibrium in the analysis domain could be achieved after tens of thousands of iterations. At the second stage, the displacement constraint where the two openings were located were removed simultaneously or successively to simulate the different excavation sequences.

The detailed studied parameter design of the numerical experiments was shown in Table 1.

Series a was aimed to compare the difference of the characteristics of the pressure arch between the twin-parallel openings and the single opening. The numerical model of case al was only designed with one opening, and the other settings were the same as case a2.

Series $b$ was designed to reveal the effect of joint's strength. To simplify the analyzing process, only the friction angle of the joints $(\varphi)$ was selected as the representative parameter to reflect the strength of the joints. The friction angel in this series varied as $5^{\circ}, 10^{\circ}, 15^{\circ}, 20^{\circ}, 25^{\circ}, 30^{\circ}$, and the other parameters were kept constant.

Series $c$ was employed to reflect the influence of the in situ stress ratio $\left(K_{0}\right)$. The values of the in situ stress ratio were chosen as $0.3,0.5,0.7,1,1.2$, and the other parameters were fixed. The cases were numbered as c1-c5 in Table 1.

Series $d$ focused on the effect of the distance between the two openings $(L)$. The distance value varied as $5 \mathrm{~m}, 10 \mathrm{~m}$, $15 \mathrm{~m}, 20 \mathrm{~m}, 30 \mathrm{~m}, 40 \mathrm{~m}, 50 \mathrm{~m}$. The other parameters remained unchanged. The cases were designated as $\mathrm{d} 1-\mathrm{d} 7$, which are shown in Table 1.

Series $e$ were conducted to examine the influence of the excavation sequence. There were two excavation situations considered in this study. In the first situation, two openings were excavated at the same time. In the second situation, one opening was excavated firstly, and after achieving the stress equilibrium, the other opening started to be excavated. The other parameters remained fixed. The cases were labeled by e1-e4.

\section{Results and Discussions}

To reveal the regularity related to the pressure arch above the twin-parallel openings of the jointed rock masses, the results of the numerical experiments mentioned above were analyzed in this section. The analysis domain was selected as $100 \mathrm{~m}$ width and $50 \mathrm{~m}$ height, which could speed up the data processing with ensuring the accuracy of the analysis. The middle rock wall was one of the characteristic structures of the engineering of the twin-parallel openings. The magnitude of the vertical stress in the middle rock wall was analyzed to reveal the difference among the cases in one series due to the main direction of the maximum principal stress in the middle rock wall being vertical. The directions of the maximum principal stresses in the rock masses above the opening were deflected greatly; hence the direction of the maximum principal stress of the rock masses upper the middle of the opening was analyzed to reflect the influence of the different conditions.

3.1. The Characteristics of the Stress Distribution. A representative model case (case: a2) of the twin-parallel openings was compared with the model of the single opening (case: a1). All the conditions were the same except the openings number in the two comparative cases.

The distribution of the maximum principal stress $\left(\sigma_{\max -p r i n c i p a l}\right)$ vectors after excavation is shown in Figure 2. Before the excavation, the maximum principal stress was mainly in the vertical direction, while the minimum principal stress was in the horizontal direction when the in situ ratio $\left(K_{0}\right)$ was less than 1 . The magnitude of the maximum principal stress and the minimum principal stress increased linearly with depth increasing. Following the excavation, the maximum principal stress in the vicinity of the opening was redistributed immediately. The closer to the opening, the greater the direction of the maximum principal stress deviated from the vertical direction. The characteristics of the distribution of the maximum principal stress could be discussed from the following two aspects.

3.1.1. The Partition of Rock Masses. Whether the single opening or the twin-parallel openings, according to the characteristics of the maximum principal stress vectors, the surrounding rock masses above the opening could be divided into three areas. The three areas are the local pressure arch area, the global pressure arch area, and the uninfluenced area, respectively, from the roof of the opening to the ground.

The local pressure arch area has been characterized by the obvious deflection of the maximum principal stress, especially the nearly horizontal maximum principal stress appearing. The local pressure arch could be further divided into two zones according to nearly horizontal maximum principal stress. One zone refers to the margin of this area, where the stress has significantly deflected an arch-shaped structure formed according to the arch-similar shape of the maximum principal stresses trace in this zone. The weight of the overburden has been sustained by this arch-shaped 


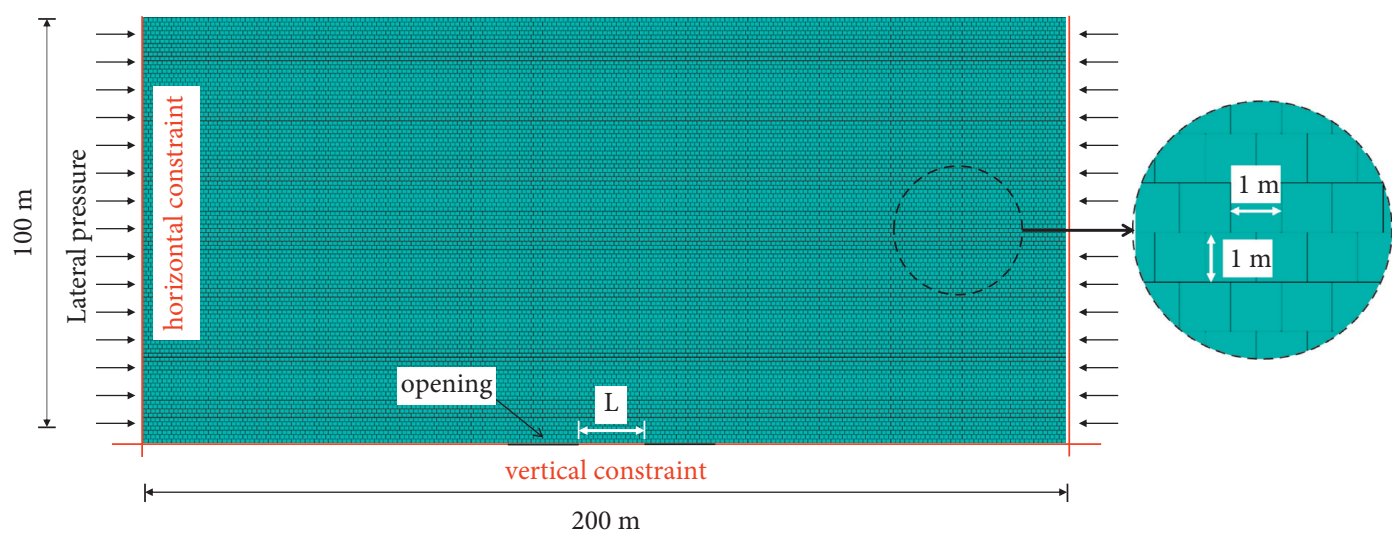

Figure 1: Numerical models used in the simulation.

Table 1: Design of the numerical experiment.

\begin{tabular}{cccccc}
\hline Series & Case & $\varphi\left(^{\circ}\right)$ & $K_{0}$ & $L$ & Excavation sequence \\
\hline \multirow{2}{*}{ a } & a1 & 20 & 0.7 & One opening & - \\
& a2 & 20 & 0.7 & 5 & One time \\
\hline \multirow{4}{*}{ b } & b1 & 5 & 0.7 & 10 & One time \\
& b2 & 10 & 0.7 & 10 & One time \\
& b3 & 15 & 0.7 & 10 & One time \\
& b4 & 20 & 0.7 & 10 & One time \\
& b5 & 25 & 0.7 & 10 & One time \\
& b6 & 30 & 0.7 & 10 & One time \\
\hline & c1 & 20 & 0.3 & 10 & One time \\
& c2 & 20 & 0.5 & 10 & One time \\
& c3 (b4) & 20 & 0.7 & 10 & One time \\
& c4 & 20 & 1 & 10 & One time \\
& c5 & 20 & 1.2 & 10 & One time \\
\hline \multirow{4}{*}{ d } & d1 (a2) & 20 & 0.7 & 5 & One time \\
& d2 (b4) & 20 & 0.7 & 10 & One time \\
& d3 & 20 & 0.7 & 15 & One time \\
& d4 & 20 & 0.7 & 20 & One time \\
& d5 & 20 & 0.7 & 30 & One time \\
& d6 & 20 & 0.7 & 40 & One time \\
& d7 & 20 & 0.7 & 50 & One time \\
\hline \multirow{4}{*}{ e } & e1 (b4) & 20 & 0.7 & 10 & One time \\
& e2 & 20 & 0.7 & 10 & Two times \\
& e3 & 5 & 0.5 & 10 & One time \\
e4 & 5 & 0.5 & 10 & Two times \\
\hline & & & & &
\end{tabular}

structure and has been transferred to the abutments. Beneath this structure is the other zone; the maximum principal stress of the rock mass has changed from the vertical to the almost horizontal direction. The stress state of this zone is like a beam and presents the rock masses that only support its own weight, and this zone could also be named the loosened zone. In this zone, the rock masses have no longer resisted the overlying pressure, and two common failure modes of the rock masses could be generated under their own weight, including sliding failure along the joints and the snap-through failure, as shown in Figure 3.

The mechanism of the sliding failure of the rock masses under the arch structure in the local pressure arch area is illustrated in Figure 4. The beam concept in mechanics is used in the following analysis. The stability of the beam highly depends on the shear resistance provided by the joints. The maximum shear stress $\tau_{\max }$ in the beam is as follows:

$$
\tau_{\max }=\frac{b q}{2 h},
$$

where $b$ was the wide of the opening, $q$ was the pressure of the overburden weight, $h$ was the thickness of the beam.

Supposing that the shear strength of the joints was $\tau_{f}$, and according to the Mohr-Coulomb model,

$$
\tau_{f}=\sigma f_{k},
$$

where $\sigma$ referred to the normal stress in the joints' face and could be computed by $\sigma=K_{0} q, K_{0}$ was the in situ stress ratio. $f_{k}$ was expressed by $f_{k}=c / \sigma+\tan \varphi$, and $c$ was the cohesion, $\varphi$ was the friction angle. The stability condition could be obtained as follows:

$$
h=\frac{0.5 b}{K_{0} f_{k}} .
$$

It could be seen that the magnitude of the $K_{0}$ was a key factor to ensure the beam sustainable.

The other possible failure mode is a snap-through failure. The theory of the thrust line based on the arch structure could be used to assess the possibility of this type of failure $[21,22]$. The thrust line is a curve representing the equilibrium of the beam under the vertical loading. The snapthrough failure shall happen when the thrust line exceeds the beam upper boundary, as shown in Figure 3. The mechanical calculation model is shown in Figure 4. The position of the thrust line could be computed as follow.

Assume one point $i(x, y)$ located on the thrust line, the bending moment $(M)$ of this point could be given by the following:

$$
M=\frac{q x}{2}(b-x)-H y .
$$

Let $M=0$, the position of the thrust line could be obtained as follows:

$$
y=\frac{q x}{2 H}(b-x) .
$$




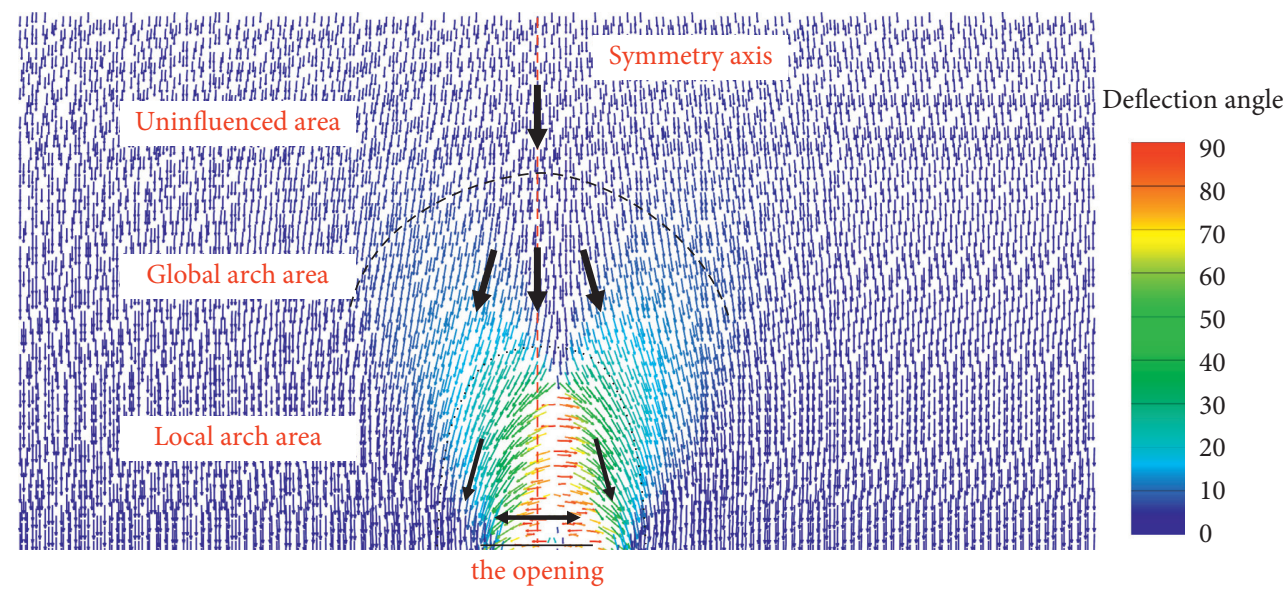

(a)

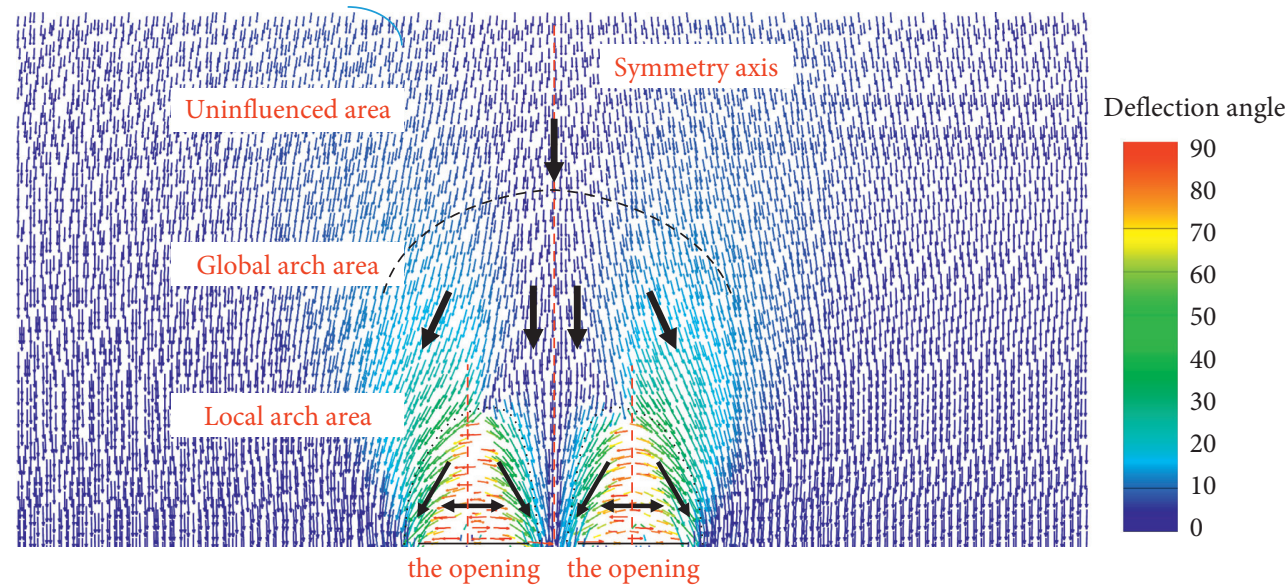

(b)

Figure 2: The maximum principal stress vector after excavation. (a) Case a1, single opening; (b) Case a2, twin-parallel opening.

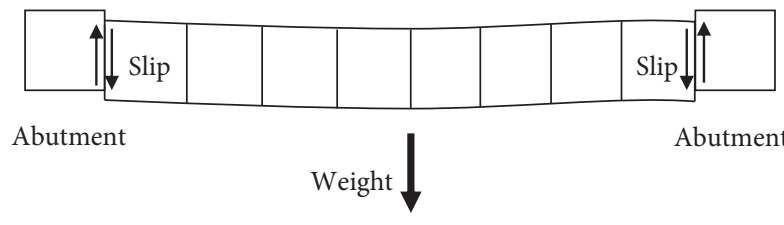

(a)

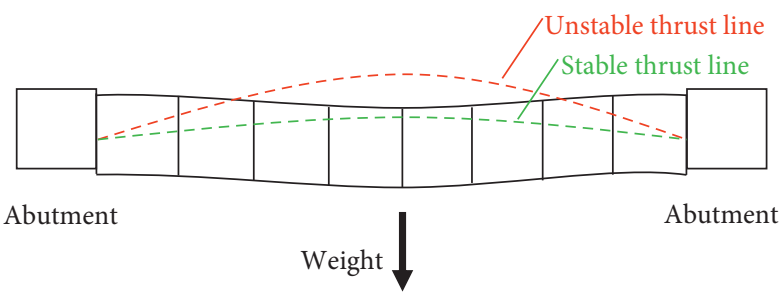

(b)

Figure 3: The failure modes of the loosened zone. (a) The slip failure; (b) The snap failure.

It could be seen that the horizontal force $H$ has a significant influence on the position of the thrust line. Furthermore, the in situ ratio has determined the possibility of the occurrence of the snap-failure.

The global pressure arch area is above the local pressure arch area, and the extent of the maximum principal stress deflection is much less than the local pressure arch area. There is no horizontal stress. The maximum principal stresses in the middle of this area are almost vertical. The rock masses in this area have mainly acted as a stress-transfer role, and it could be considered as a transition area of the stress redistribution.

Over the global arch area, the stress state of rock masses has no obvious variation. The maximum principal stress has remained in the vertical direction and linearly increased with the depth.

It must be noted that the separation of the middle rock wall around the opening is relative complexity. The middle rock wall should not be totally contained in the local pressure arch. Only the part in which the direction of the 


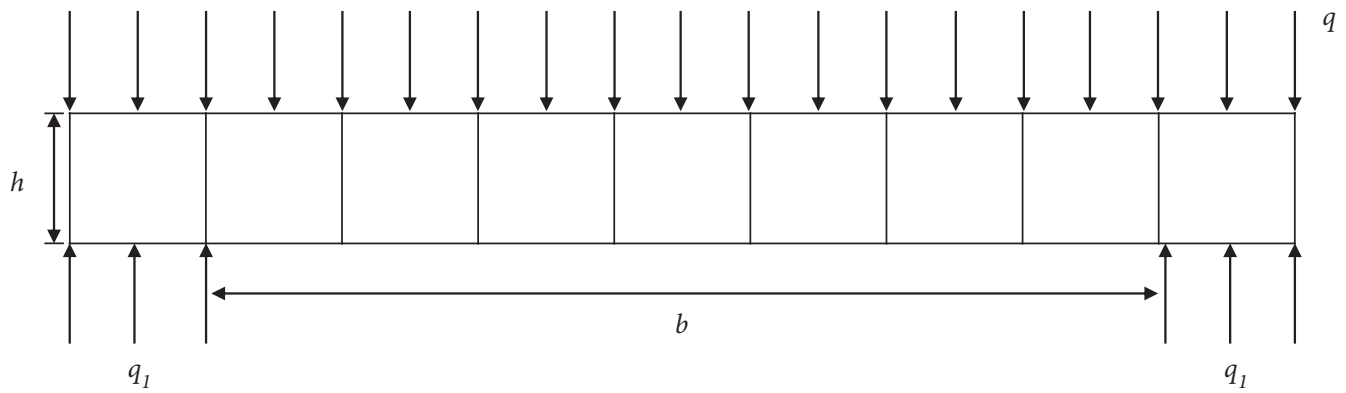

(a)
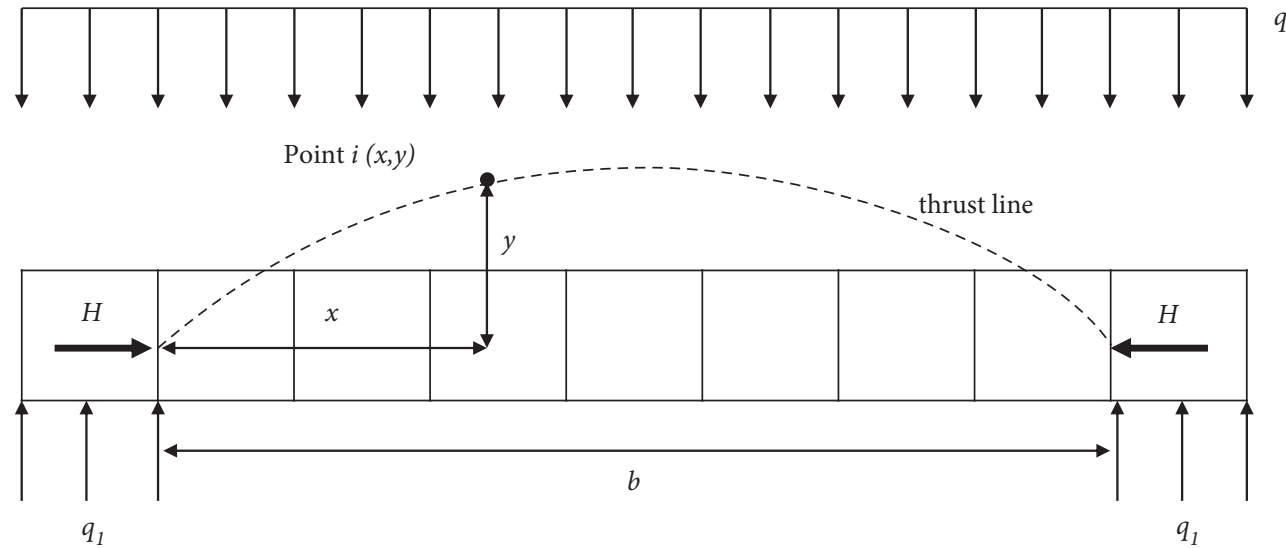

(b)

FIgURE 4: The mechanical model of the loosened zone. (a) The slip failure; (b) The snap-through failure.

principal stress has been significantly shifted could be considered in the area of the local pressure arch. And the middle part of the middle rock wall could not be classified as any separation due to the principal stress being still vertical. The area of the middle rock wall which is above the local pressure arch, could be considered as part of the global arch area, following the partition principle described in this paper.

3.1.2. The Differences between the Single Opening and the Twin-Parallel Openings. In the single opening condition, the stress distribution is symmetric around the middle line of the opening, whereas the axis of symmetry changes to the middle line of the middle rock wall, and the stress in the vicinity of one opening has not been symmetry around the middle line of the opening in the condition of the twinparallel opening.

On the single opening condition, the directions of the maximum principal stress of the rock masses on the left of the symmetry axis shift to the left, and the right points to the right. However, under the condition of the twin-parallel openings, although the directions of the maximum principal stress have been symmetry about the middle line of the middle rock wall, the directions of rock masses on the one side of the symmetry axis are not unanimous. Three areas could be divided based on the direction of the maximum principal stress, as shown in Figure 5. The formation mechanism of this phenomenon could be illustrated as follow.

Assuming one single opening, the direction of the maximum principal stress is symmetrical around the middle line of the opening: the stress on the left of the symmetry axis shifts to the left, and the right stress points to the right. Consider the twin-parallel openings, when the distance of the two openings is small. The resultant stress could be computed as Figure 5. The magnitudes of the stresses induced by the two openings at the same position in area 1 are nearly equal, and the directions of the stresses are almost symmetrical; hence the directions of the resultant stress in area 1 are almost vertical. In area 2 , the directions of the resultant stress are different between the upper and lower section. To illustrate the reason for the difference, the left half of the model is taken as an example. In the upper of area 2, the stresses induced by the left opening (the stress vector coloured by green in Figure 5) slightly deflects and points to the right side. The stresses induced by the right opening (the stress vector colored by red in Figure 5) mainly point to the left side. The horizontal components of the red stress vectors are bigger than the green stress vectors. It results in the resultant stress (the resultant stress vector colored by black in Figure 5) pointing to the left. Following the depth increases, the direction of the red stress vectors gradually changes to the vertical direction, and the horizontal component of the red stress is inadequate to offset the horizontal component of the green stress; hence the resultant stress 


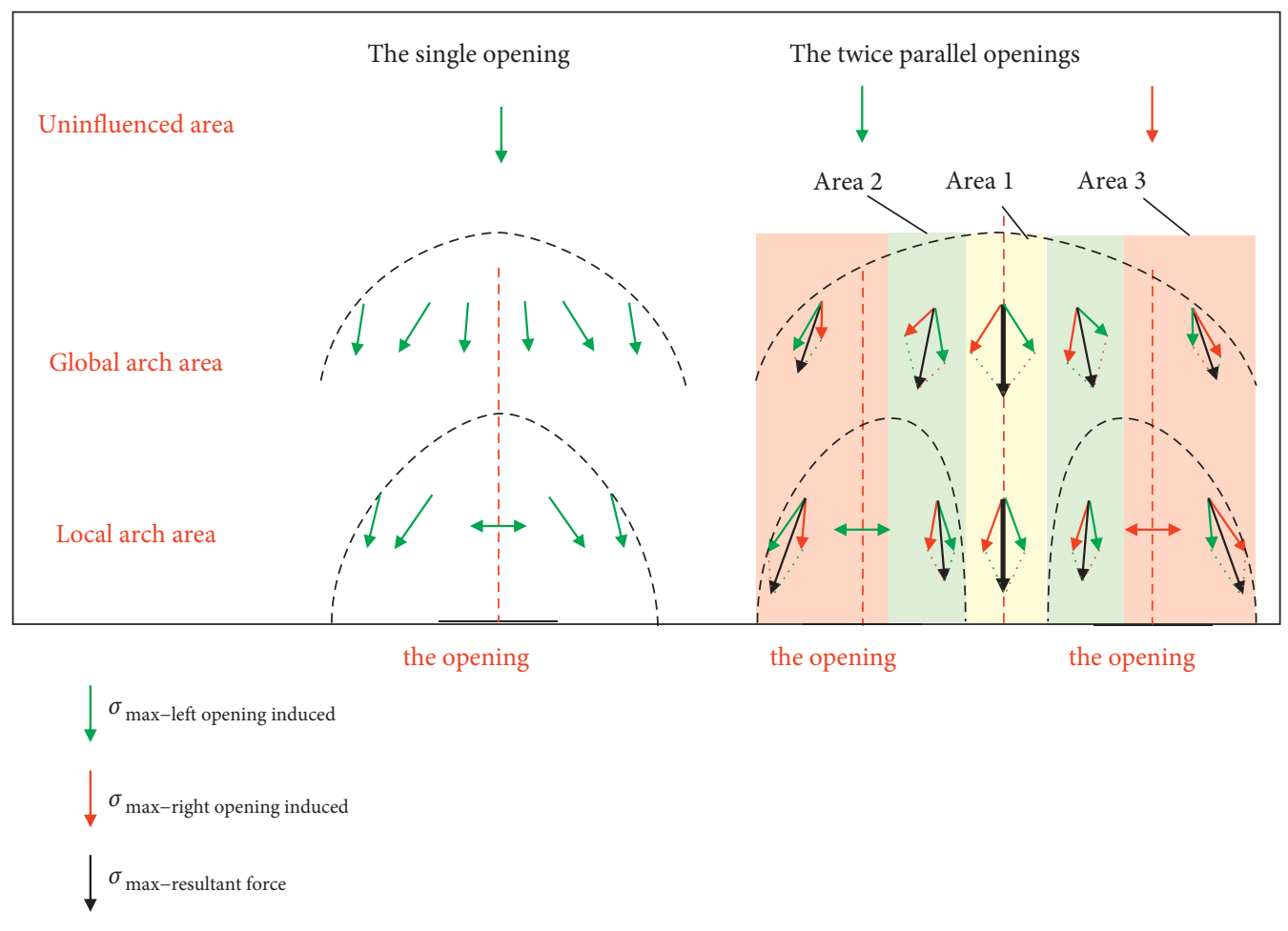

Figure 5: The mechanical analysis of the direction of the maximum principal stress of the rock masses.

gradually points to the right again. The direction of the maximum principal stresses in area 3 is consistent with the stress distribution of the single opening condition due to the directions of stress induced by two openings being similar.

3.2. Effect of the Joints' Strength. To examine the effect of the joint's strength on the formation of the pressure arch, six cases with the friction angle $(\varphi)$ of the joints from $5^{\circ}$ to $30^{\circ}$ were designed and simulated (case: b1-b6). Cohesion was not considered in this paper because it could simplify the process of computing and result in analysis using one parameter to evaluate the joint's strength.

3.2.1. The Stress in the Middle Rock Wall. As mentioned above, the maximum principal stresses of the middle rock wall have mainly pointed to the vertical direction. Therefore, the differences between the cases in series $b$ have mainly concentrated on the magnitude of the vertical stress. A survey line is set along the middle of the middle rock wall; the stress of the points located on or near this line could be obtained. The curves of the vertical stress versus the distance to the opening are shown in Figure 6.

There are two distinctly different parts of the change of the stress along the middle line of the middle rock wall. In the first part, the stresses have exceeded the origin in situ stress and increased with the decreasing of the distance to the opening (the red area in Figure 6). It indicates that the pressure arch delivers the overlaying stress to the middle rock wall. The increment of the stress has induced the additional strain, and the additional strain of the rock masses of this area has offered the deformation space for

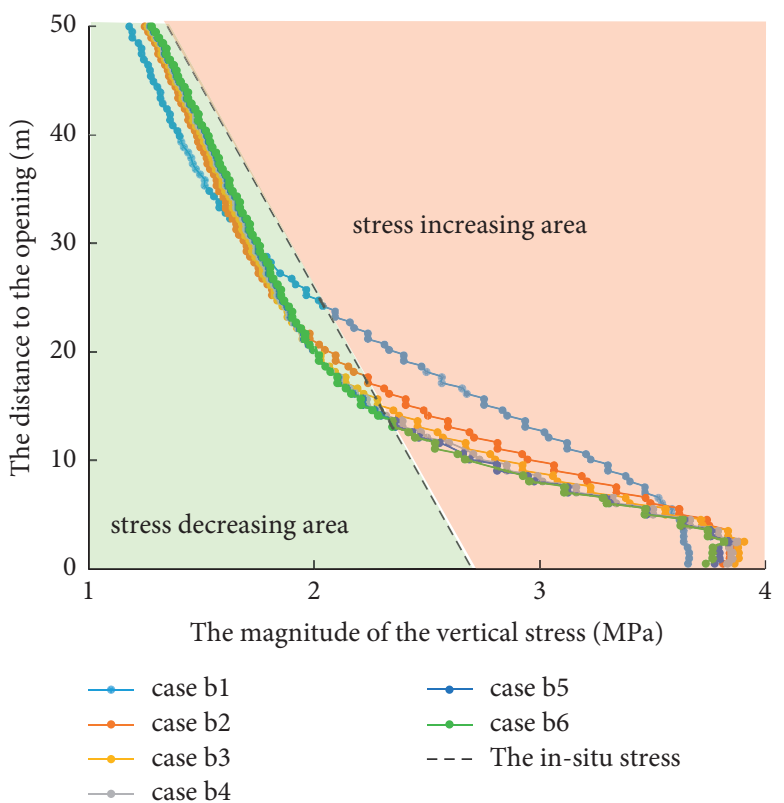

Figure 6: The relationship between the vertical stress and the distance to the opening.

the upper rock masses. The stress relief shall occur in the upper of the middle rock wall immediately, and then the stresses of the upper rock masses have fallen below the in situ origin stress, as shown in the green area in Figure 6. The curves in the green area are the second part mentioned above. The in situ stress could be computed by the formula " $\rho g h$ ". This process has been illustrated in Figure 7. 


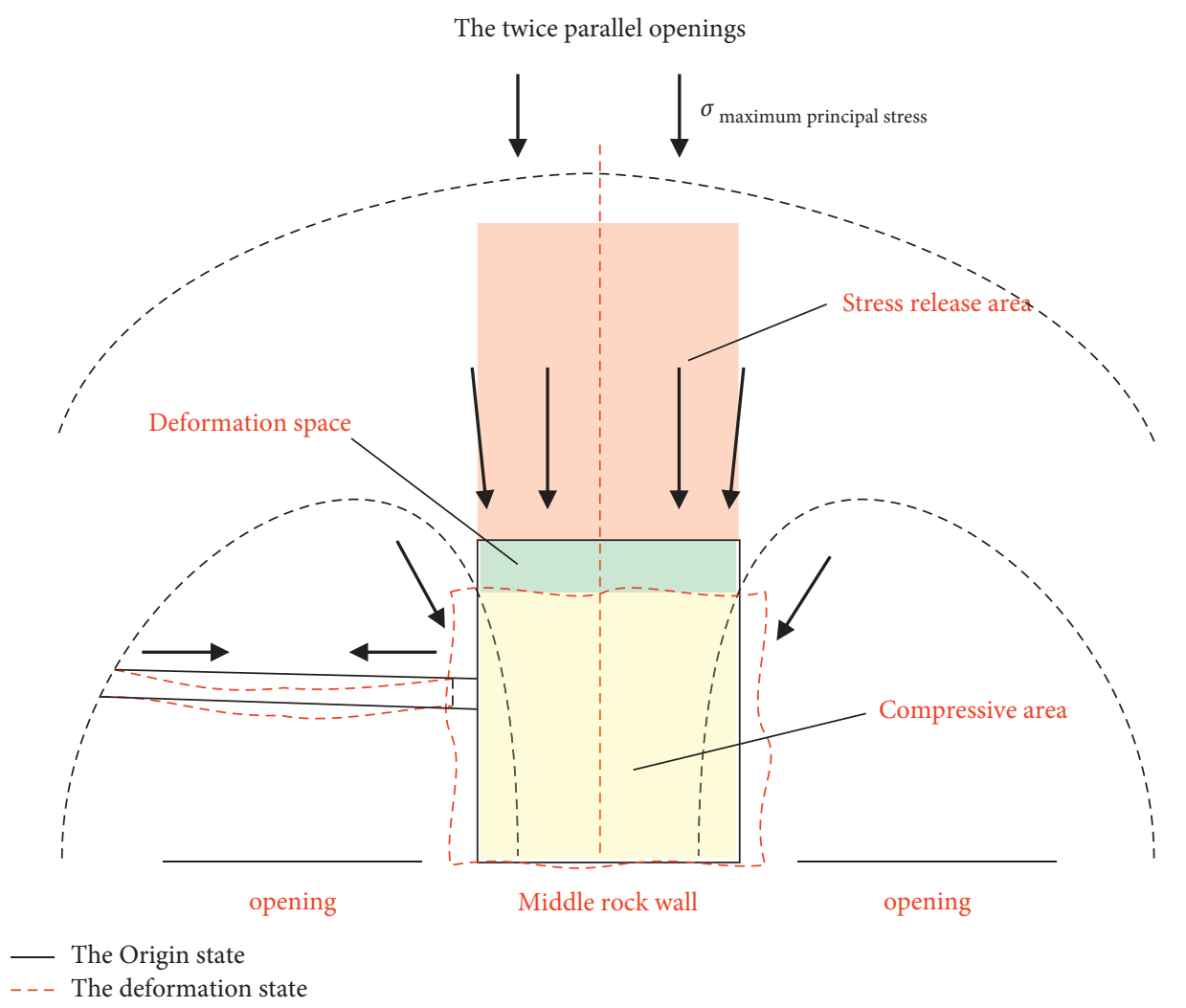

FIGURE 7: The illustration of the stress change in the middle rock wall.

With the increasing of the friction angle $(\varphi)$ of the joints, the magnitude of the stresses is different at the same distance to the opening. When closing to the opening, the smaller friction angle $(\varphi)$ of the joints leads to the greater stress. It means that the greater overlying pressure, which is applied on the local pressure arch, could be formed in the rock masses with the lower joint's strength. In other words, the local pressure arch shall transfer the greater overlying stress to the middle rock wall when the strength of joints is lower. The greater stress results in the greater strain of the lower part of the middle rock wall and the greater release space for the upper rock masses, and then the stress decrease of the upper rock masses is increased. Hence, the stress is lower when the friction angle $(\varphi)$ is lower at a far distance to the opening, as shown in the green area in Figure 6.

3.2.2. The Stress above the Opening. The direction of the maximum principal stress of the rock masses above the opening was selected as an indicator to reveal the influence of different friction angle $(\varphi)$ of joints. The curves of the direction of the maximum principal stress, which is defined by the angle between the stress and the horizontal direction versus the distance to the opening, are shown in Figure 8.

When the distance to the opening is large, the stress vector mainly points to the vertical, and the amplitude of direction change is small (Section 1 in Figure 8). And then, the vector changes to horizontal quickly until nearly approaching the horizontal direction (Section 2 in Figure 8). Finally, the stress was mainly along the horizontal

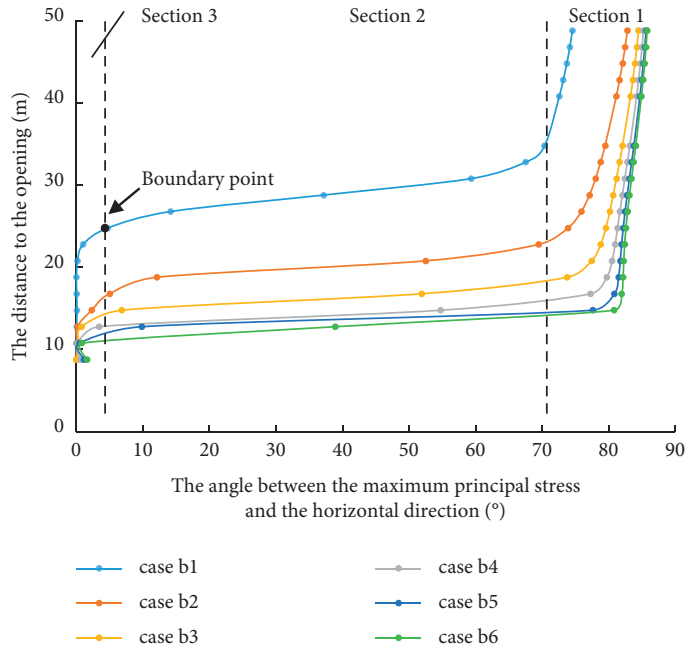

FIGURE 8: The relationship between the direction of the maximum principal stress and the distance to the opening.

direction and almost no longer changed with the distance decreasing (Section 3 in Figure 8). A typical point, as shown as the boundary point in Figure 8, could be noticed. Below this point, the maximum principal stress has begun to shift to the horizontal, which means that the area below this point is the local pressure arch, according to the definition of the local pressure arch in this paper. In other words, this point could be regarded as the upper boundary of the local arch. 
The greater the friction angle $(\varphi)$ of the joints, the smaller the distance between the boundary point and the opening. It shows that the local pressure arch position has a close relationship with the strength of joints, and the higher strength rock masses could lead to the lower local arch. The approximate distance between the boundary point and the opening is $23 \mathrm{~m}$ in case a1, whereas only $15 \mathrm{~m}$ in case a 2 with the friction angle $(\varphi)$ of the joints has been only improved $5^{\circ}$. From case a2 to case a6, the increment of the friction angle of the joints is $20^{\circ}$. However, the distance between the boundary point and the opening has been changed to $5 \mathrm{~m}$. The upper boundary of the local arch has an obvious change with the variation of the joint' $s$ strength when the joint's strength is relatively small, to put it differently, the position of the local pressure arch has been more sensitive to the changes of the joints' strength when joints' strength is small.

\subsection{Effect of the In Situ Stress Ratio}

3.3.1. The Stress in the Middle Rock Wall. The curves of the magnitude of the vertical stress versus the distance to the opening are shown in Figure 9. The vertical stress in the middle rock wall could not be significantly affected by the change of the in situ ratio $\left(K_{0}\right)$. The vertical stress of the upper rock masses of the middle rock wall has been released due to the compression deformation of the lower rock masses, and the value of vertical stress of the upper rock masses in the middle rock wall has decreased to below the in situ vertical stress, whereas the lower has increased to exceed the in situ stress, as mentioned above.

3.3.2. The Stress above the Openings. The curves of the angle between the maximum stress and the horizontal direction versus the distance to the opening have been plotted in Figure 10. The curves of the cases with different in situ stress ratios have presented two typical shapes, which means there are two different characteristics of the stress distribution while the in situ ratio is bigger than 1 or less than 1 . When the in situ ratio is less than 1 and the distance to the opening is large, the maximum principal stress has mainly pointed to the vertical direction and is slightly deflected. Following the distance decreases, the direction of the stress has rapidly changed to the horizontal in the several meters. And then, the stress has mainly pointed to the horizontal direction. However, when the in situ ratio is greater than 1 , the origin maximum principal stress has pointed to the horizontal direction before the opening excavating. After the excavation, the stress has been redistributed, and the direction of the stress of the rock masses, which are relatively far from the opening, have slightly shifted to the vertical. And with the distance to the opening decreasing, the direction of the stress has gradually recovered the horizontal direction.

When the in situ ration is larger than 1, the arch structure would no longer mainly transfer the overlying pressure to the abutments. The overlying pressure is generally considered to be induced by the weight of the overlying rock masses. The lateral pressure would be the main force that the arch should bear. The mechanism of the arch

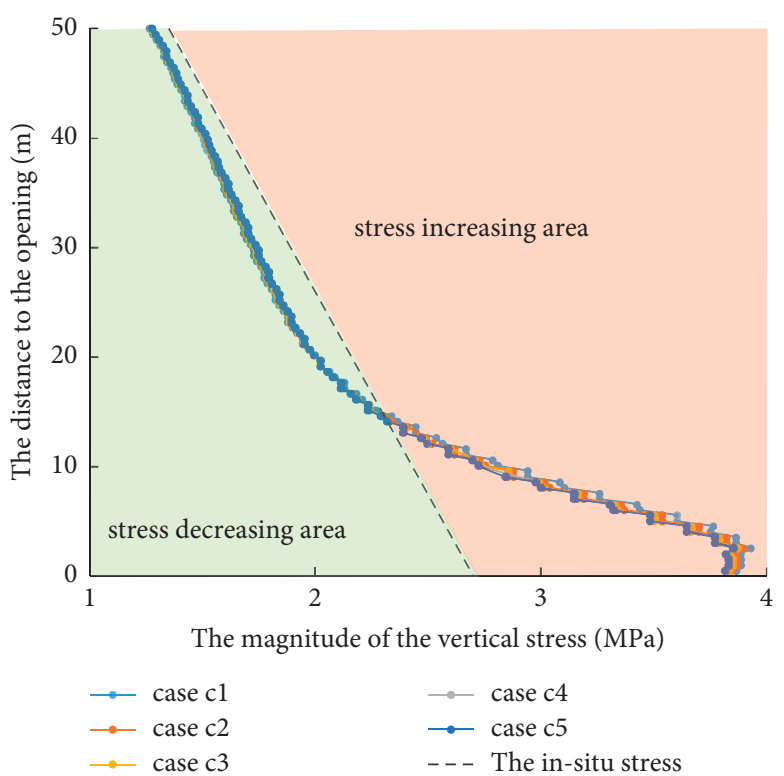

Figure 9: The relationship between the vertical stress and the distance to the opening.

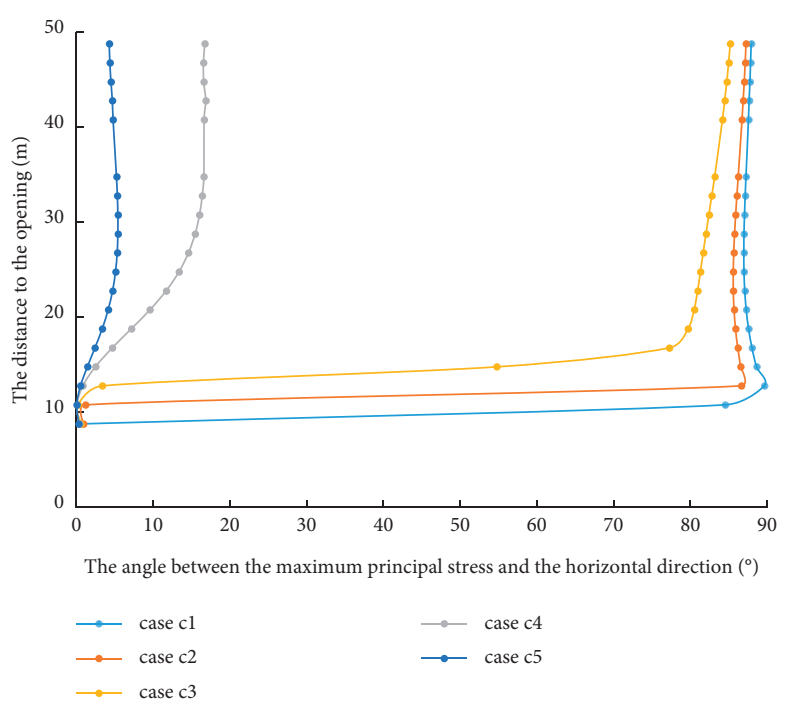

FIgURE 10: The relationship between the direction of the maximum principal stress and the distance to the opening.

formation and deformation should be thoroughly reanalyzed.

\subsection{Effect of the Distance of the Twin-Parallel Openings.} Seven cases with varies $L$ (the distance between the two openings, or the width of the middle rock wall) of $5 \mathrm{~m}, 10 \mathrm{~m}$, $15 \mathrm{~m}, 20 \mathrm{~m}, 25 \mathrm{~m}, 30 \mathrm{~m}, 40 \mathrm{~m}, 50 \mathrm{~m}$ were considered to reveal the effect of the distance between the two openings. The vertical stress of the middle rock wall and the direction of the maximum principal stress has been analyzed in this section.

3.4.1. The Stress in the Middle Rock Wall. Similar to the previous series, a survey line is set along the middle of the 


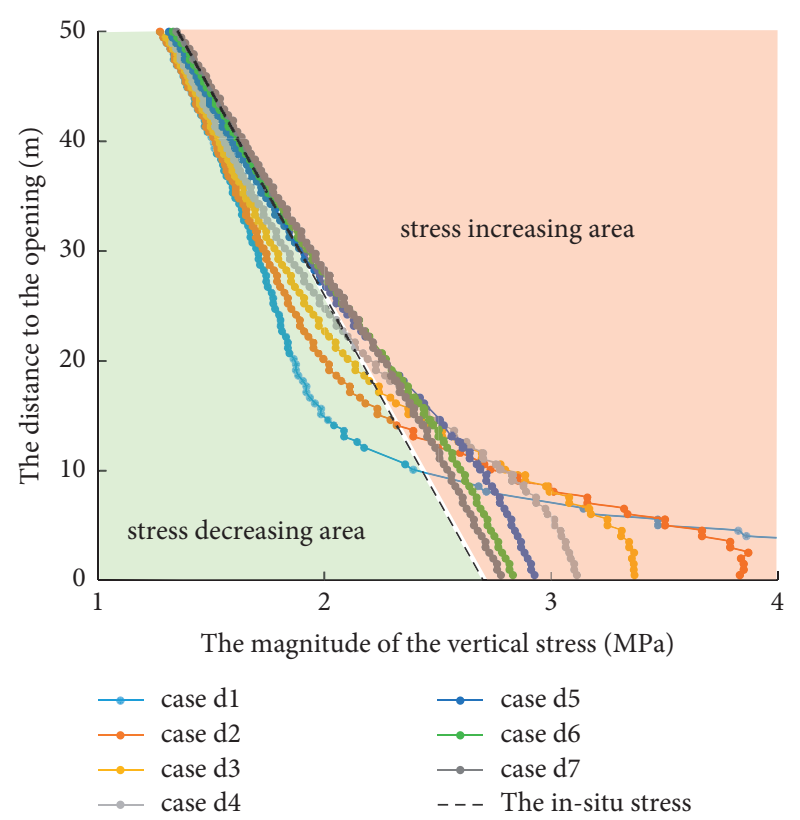

Figure 11: The relationship between the vertical stress and the distance to the opening.

middle rock wall, and the stress of the points located on or near this line has been extracted. The curves of the vertical stress versus the distance to the opening are shown in Figure 11.

As shown in Figure 11, the larger the distance between the two openings $(L)$, the closer the vertical stress curves and the in situ stress line are to each other. Especially, in case d6 $(L=40 \mathrm{~m})$ and case $\mathrm{d} 7((L=50 \mathrm{~m})$, the stress curves have almost coincided with the in situ stress line. It shows that the neighbor opening has nearly no effect on the other opening when their distance is greater than $40 \sim 50 \mathrm{~m}$ in the model of this paper.

Besides, the shape characteristic of the curves of the different cases has been mainly consistent. As analyzed above, the vertical stress has exceeded the in situ origin stress in the rock masses closing to the opening, and the compression deformation of the lower rock masses induces the stress relief of the upper rock masses in the middle rock wall. This shape characteristic could not change with various distances between the two openings $(L)$.

3.4.2. The Stress above the Openings. The curves of the angle between the maximum principal stress and the horizontal direction versus the distance to the opening with various $L$ have been shown in Figure 12.

The results have presented a certain fluctuation among the different cases in the series $d$; however, it could still reflect some regularity with the change of the distance between the two openings $(L)$. The main characteristic of the curves of the different cases has remained unanimous with the previously analyzed. In the upper of the rock masses above the opening (approximately $h>15 \mathrm{~m}$ in this paper), the deflection angle of the direction of the stress has gradually decreased with the $L$ (the distance between the two

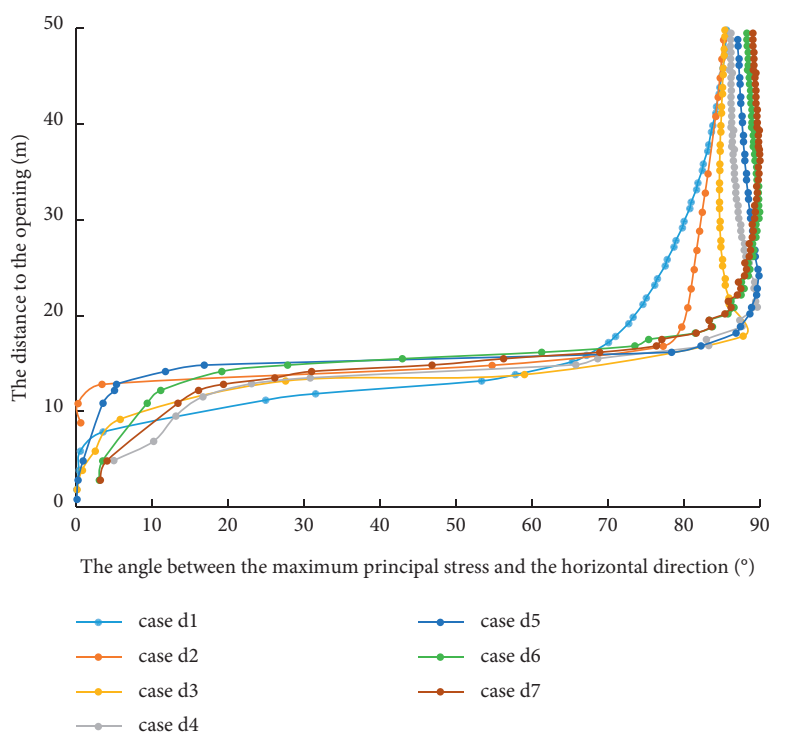

FIGURE 12: The relationship between the direction of the maximum principal stress and the distance to the opening.

openings) increasing at the same distance to the opening. The influence of the neighbor opening on the other opening has been obviously weakened with the $L$ increasing. The position of the boundary point, which is considered as the upper boundary of the local arch in this paper, has decreased from case $\mathrm{cl}(L=5 \mathrm{~m})$ to case $\mathrm{c} 7(L=50 \mathrm{~m})$. It shows that the pressure acting on the local pressure arch has decreased with the $L$ (distance between the two openings) increasing. In other words, the neighbor opening has induced the weakening of the rock masses strength and the increment of the overlying pressure. The influence would be weakened with the $L$ (the distance between the two openings) increasing.

3.5. Effect of the Excavation Sequence. To investigate the influence of the excavation sequence, the series $e$ was designed. Firstly, cases e1 and e2, which had the same parameter values, were compared. However, there were no obvious differences between cases e 1 and e2, according to the magnitude of the vertical stress in the middle rock wall and the direction of the maximum principal stress above the opening.

Considering that the reason for no obvious difference between case e 1 and e 2 was that there was no collapse in these two cases, and the stress in case e 2 could be recovered after the neighbor opening excavating. Case e3 and case e4, in which the collapse could occur, were employed to further research. However, it is still not significantly changed between cases e 3 and e4. Hence, it could be concluded that the sequence of the excavation has only a slight impact on the deformation of the rock masses above the opening.

The curves of the magnitude of the vertical stress in the middle rock wall and the direction deflection of the maximum principal stress versus the distance to the opening have been shown in Figures 13 and 14, respectively. And the curve of case e1 has been almost covered by case e 2 in Figure 13. 


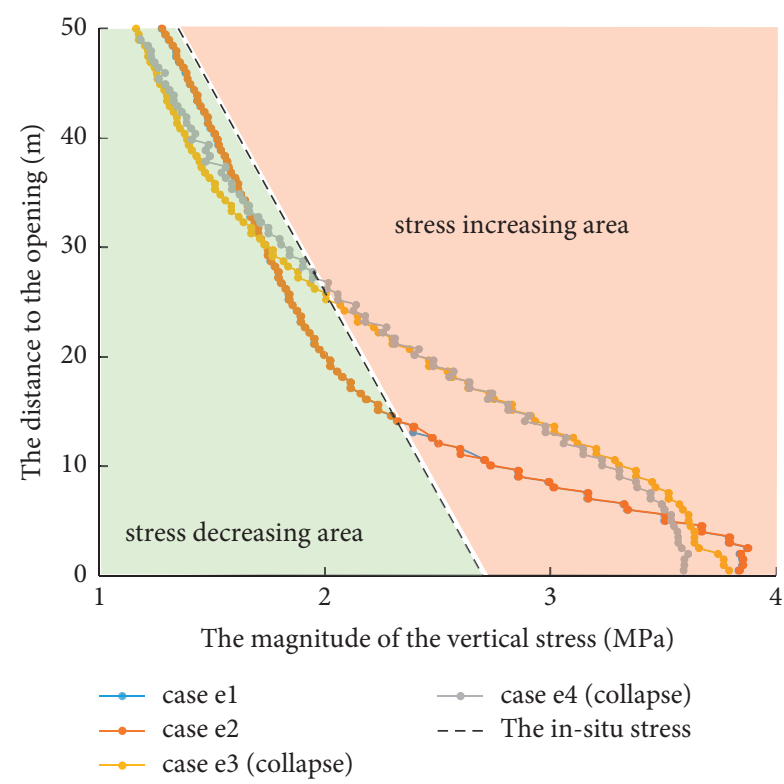

FIgURE 13: The relationship between the vertical stress and the distance to the opening. The rock masses in cases e 1 and e 2 are not collapsed, whereas the collapse has occurred in cases e3 and e4.

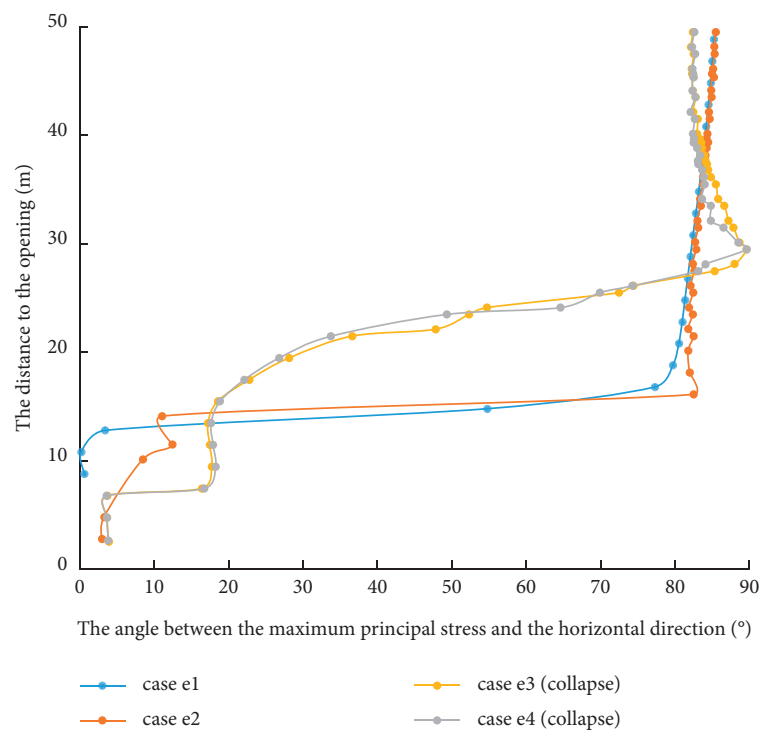

FIGURE 14: The relationship between the direction of the maximum principal stress and the distance to the opening.

\section{Conclusion}

In this paper, the characteristics of pressure arch above the twin-parallel openings in the jointed rock masses were studied using the DEM method. Five series of numerical experiments were conducted with different research parameters. The joint's strength $(\varphi)$, the in situ ratio $\left(K_{0}\right)$, the distance between the two openings $(L)$, and the excavation sequence were considered as the examined variables, respectively. The followings are mainly conclusions obtained in this paper.
(1) Whether single opening or the twin-parallel openings, the rock masses above the opening could be divided into three areas based on the direction of the maximum principal stress after excavation. The local arch area, which is closed to the opening, is characterized by the heavy deflection of the maximum principal stress and the appearance of the horizontal maximum principal stress. The local arch area could be further divided into two zones, including the zone of the margin of this area where the heavy deflection of the maximum principal stress has been distributed, and the zone of the loosened rock masses where the horizontal maximum principal stress has been mainly appearance. The global arch area, which is above the local area, is generally symmetric of the middle line of the opening (the single opening condition) or the middle line of the middle rock wall (the twin-parallel opening condition). The uninfluenced area, which is located above the global area, is the area that the maximum principal stress remains vertical as before excavating.

(2) There are two modes of failure which could occur in the loosened zone of the local arch area, including the sliding failure and the snap-through failure. The mechanical analysis of the two modes has been given in this paper, respectively.

(3) The differences in the distribution of the maximum principal stress above the opening between the single opening and the twin-parallel openings are mainly focused on the stress distribution around the area of the middle rock wall. In the twin-parallel openings situation, although the maximum principal stresses are still symmetrical about the middle line of the middle rock wall, the stresses around the opening are no longer symmetrical about the middle line of the opening. Besides that, the directions of the maximum principal stresses around the middle rock wall are not unique. The mechanism of this phenomenon has been illustrated using the superposition of stresses.

(4) The lower friction angle $(\varphi)$ leads to the lower strength of the joints, and the lower strength of joints could result in the greater overlying pressure and the higher position of the local arch. The stress change is more sensitive to the friction angle $(\varphi)$ when the friction angle $(\varphi)$ is lower, including the magnitude of the vertical stress in the middle rock wall and the direction of the maximum principal stress above the opening.

(5) The in situ stress ratio $\left(K_{0}\right)$ has a key impact on the failure modes of the loosened zone, according to the mechanical analysis. Besides, the directions of the maximum principal stresses above the opening have also been strongly influenced by the in situ stress ratio $\left(K_{0}\right)$. At the same distance to the opening, the greater the in situ stress ratio $\left(K_{0}\right)$, the greater the maximum principal stresses are deflected. However, 
the magnitude of the vertical stress in the middle rock wall has been slightly impacted with the in situ stress ratio changing. It is worth noting that the distribution of the in situ maximum principal stress has been distinctly different when the in situ stress ratio is bigger than 1 or less than 1 , and this could result in the different deformation mechanisms of the rock arch. When the in situ stress ratio is bigger than 1, all the conclusions should be reanalyzed thoroughly.

(6) The influence of the neighbor opening has been decreased with the increasing of the distance between the two openings $(L)$, according to the magnitude of the vertical stress in the middle rock wall and the direction of the maximum principal stress above the opening. In this paper, when $L \geq 40 \sim 50 \mathrm{~m}$, the influence has been weak. Besides, the pressure of the local arch bearing has also been decreased with the increase of the $L$, which could be reflected by the change of the upper boundary of the local arch.

(7) There is no obvious difference between the once excavation and the twice excavation in the models of this paper, whether the collapses occur or not. The excavation sequence has a slight influence on the deformation or the movement of the rock masses above the opening.

\section{Data Availability}

The data used in this study have already been posted in this paper.

\section{Conflicts of Interest}

The authors declare that there are no conflicts of interest regarding the publication of this paper.

\section{References}

[1] D. Kong, Y. Xiong, Z. Cheng, N. Wang, G. Wu, and Y. Liu, "Stability analysis of coal face based on coal face-support-roof system in steeply inclined coal seam," Geomech Eng, vol. 25, no. 3, pp. 233-243, 2021.

[2] Z.-Q. Yang, C. Liu, F.-S. Li, L.-M. Dou, G.-W. Li, and D.-W. Wang, "The mechanism and application of highpressure water jet technology to prevent compound dynamic disaster," Arabian Journal of Geosciences, vol. 14, 2021.

[3] H. Wu, D. Ma, A. J. S. Spearing, and G. Zhao, "Fracture phenomena and mechanisms of brittle rock with different numbers of openings under uniaxial loading," Geomechanics and Engineering, vol. 25, no. 6, pp. 481-493, 2021.

[4] D. Kong, S. Pu, Z. Cheng, G. Wu, and Y. Liu, "Coordinated deformation mechanism of the top coal and filling body of gob-side entry retaining in a fully mechanized caving face," International Journal of Geomechanics, vol. 21, Article ID 4021030, 2021.

[5] J. Chen, P. Liu, H. Zhao, C. Zhang, and J. Zhang, "Analytical studying the axial performance of fully encapsulated rock bolts," Engineering Failure Analysis, vol. 128, Article ID 105580, 2021.
[6] J. Chen and D. Li, "Numerical simulation of fully encapsulated rock bolts with a tri-linear constitutive relation," Tunnelling and Underground Space Technology, vol. 120, Article ID 104265, 2022.

[7] L. V. Rabcewicz, "The new austrian tunnelling method," Water Power, vol. 65, 1964.

[8] H. Yoshimura, T. Yuki, Y. Yamada, and N. Kokubun, "Analysis and monitoring of the Miyana railway tunnel constructed using the New Austrian tunnelling method," International Journal of Rock Mechanics and Mining Sciences \& Geomechanics Abstracts, vol. 23, no. 1, pp. 67-75, 1986.

[9] C. W. Ng, K. M. Lee, and D. K. Tang, “Three-dimensional numerical investigations of new Austrian tunnelling method (NATM) twin tunnel interactions," Canadian Geotechnical Journal, vol. 41, no. 3, pp. 523-539, 2004.

[10] N. E. Yasitli, "Numerical modeling of surface settlements at the transition zone excavated by New Austrian Tunneling Method and Umbrella Arch Method in weak rock," Arabian Journal of Geosciences, vol. 6, no. 7, pp. 2699-2708, 2013.

[11] A. R. Sogut and E. Eser, "Engineering geological investigations of T-11 tunnel along Burdur-Antalya high-speed railway," Arabian Journal of Geosciences, vol. 13, no. 16, 2020.

[12] C. C. Li, "Rock support design based on the concept of pressure arch," International Journal of Rock Mechanics and Mining Sciences, vol. 43, no. 7, pp. 1083-1090, 2006.

[13] D. Bakun-Mazor, Y. H. Hatzor, and W. S. Dershowitz, "Modeling mechanical layering effects on stability of underground openings in jointed sedimentary rocks," International Journal of Rock Mechanics and Mining Sciences, vol. 46, no. 2, pp. 262-271, 2009.

[14] H. Asaei, M. Moosavi, and M. A. Aghighi, "A laboratory study of stress arching around an inclusion due to pore pressure changes," Journal of Rock Mechanics and Geotechnical Engineering, vol. 10, no. 4, pp. 678-693, 2018.

[15] C. N. Chen, W.-Y. Huang, and C.-T. Tseng, "Stress redistribution and ground arch development during tunneling," Tunnelling and Underground Space Technology, vol. 26, no. 1, pp. 228-235, 2011.

[16] C. Jin, A. Shao, D. Liu, T. Han, F. Fan, and S. Li, "Failure mechanism of highly stressed rock mass during unloading based on the stress arch theory," International Journal of Geomechanics, vol. 18, Article ID 4018146, 2018.

[17] S. He, D. Wang, X. Liu, and J. Zhang, "Assessment of the arching effect and the role of rock bolting for underground excavations in rock masses-a new numerical approach," Arabian Journal of Geosciences, vol. 13, no. 13, 2020.

[18] X. X. Kong, Q. S. Liu, Q. B. Zhang, Y. X. Wu, and J. Zhao, “A method to estimate the pressure arch formation above underground excavation in rock mass," Tunnelling and Underground Space Technology, vol. 71, pp. 382-390, 2018.

[19] Y. Zhao, S. Wang, Y. Zou, X. Wang, B. Huang, and X. Zhang, "Pressure-arching characteristics of fractured strata structure during shallow horizontal coal mining," Tehnicki vjesnik Technical Gazette, vol. 25, no. 5, 2018.

[20] X. Shao, L. Wang, X. Li et al., "Conversion mechanism of a continuous pressure arch structure in strip filling mining," Arabian Journal of Geosciences, vol. 14, no. 18, 2021.

[21] L. He and Q. B. Zhang, "Numerical investigation of arching mechanism to underground excavation in jointed rock mass," Tunnelling and Underground Space Technology, vol. 50, pp. 54-67, 2015.

[22] Z. Huang, E. Broch, and M. Lu, "Cavern roof stabilitymechanism of arching and stabilization by rockbolting," 
Tunnelling and Underground Space Technology, vol. 17, no. 3, pp. 249-261, 2002.

[23] S. R. Wang, X. G. Wu, Y. H. Zhao, P. Hagan, and C. Cao, "Evolution characteristics of composite pressure-arch in thin bedrock of overlying strata during shallow coal mining," International Journal of Applied Mechanics, vol. 11, no. 3, Article ID 1950030, 2019.

[24] J. K. Lee, H. Yoo, H. Ban, and W.-J. Park, "Estimation of rock load of multi-arch tunnel with cracks using stress variable method," Applied Sciences, vol. 10, no. 9, p. 3285, 2020.

[25] Y. Zhao, S. Wang, P. Hagan, and W. Guo, "Evolution characteristics of pressure-arch and elastic energy during shallow horizontal coal mining," Tehnicki vjesnik - Technical Gazette, vol. 25, no. 3, 2018.

[26] S. Wang, X. Wu, Y. Zhao, and P. Hagan, "Mechanical performances of pressure arch in thick bedrock during shallow coal mining," Geofluids, vol. 2018, Article ID 2419659, 13 pages, 2018.

[27] X. Kong, Q. Liu, Y. Pan, and J. Liu, "Stress redistribution and formation of the pressure arch above underground excavation in rock mass," European Journal of Environmental and Civil Engineering, vol. 25, no. 4, pp. 722-736, 2021.

[28] X. Wang, H. Kang, and F. Gao, "Numerical study on the formation of pressure arch in bolted gravel plate," Computers and Geotechnics, vol. 130, Article ID 103933, 2021. 